\title{
Liquid-phase hydrogenation of 1-hexene and phenylacetylene over multicomponent nickel skeleton catalysts
}

\author{
Saltanat Suimbayeva*, Zhaksyntay Kairbekov, Indira Jeldybayeva, Elmira Ermoldina \\ al-Farabi Kazakh National University Non-profit joint-stock company, Research Institute of New \\ Chemical Technologies and Materials, Almaty, Republic of Kazakhstan
}

\begin{abstract}
This paper presents the results of a study of the process of hydrogenation of 1-hexene in ethanol and phenylacetylene in a hexanewater suspension over multicomponent nickel skeleton catalysts It was demonstrated that the activity of multicomponent skeleton nickel catalysts is substantially dependent on the nature of the additives introduced into the bearing alloy. Introduction of $\mathrm{Cu}, \mathrm{Pb}$ and $\mathrm{Ta}$ leads to an increase in activity $\left(\mathrm{W}=196-295 \mathrm{~cm}^{3} / \mathrm{min}-\mathrm{gNi}\right)$. The major mechanism of the effect of emulsion composition on the rate and selectivity of hydrogenation of phenylacetylene involves a change in the coefficient of distribution of substances between the solution and the surface of the skeleton nickel catalyst. It was also shown that the presence of water, which competes with unsaturated hydrocarbons during adsorption, adversely affects the process of purification from acetylenic hydrocarbons, as well as the stereo-regular polymerization of monomer. The research results of the kinetics and direction of the processes of hydrogenation of phenylacetylene suggest significant effect of the adsorption factor, including the ratio of free energies, concentrations and spatial orientation of the molecules of the mixture components, as well as the interaction of reacting substances and hydrogen with the catalyst surface.
\end{abstract}

\section{Introduction}

One of the large-capacity processes of petrochemicals and oil refining is the catalytic hydrogenation of unsaturated hydrocarbons. Hydrogenation processes have become urgent due to the presence in the containing gaseous streams of acetylene and diene hydrocarbons impurities, the removal of which is an important task. Although a number of solventassisted liquid purification processes have been developed for the selective removal of acetylene hydrocarbons, their selective catalytic hydrogenation without involving the alkenes themselves is more economical [1-15].

The ability of metals of periodic group VIII to catalyze the reaction of double bond migration along a carbon chain and cis-trans conversion in the hydrogenation of olefincontaining hydrocarbons has been described in a number of papers [1-5]. It has been

\footnotetext{
*E-mail address: saltanat suimbayeva@mail.ru
} 
established that group VIII metals affect the character of these side reactions differently. This can be explained by the different content and state of hydrogen adsorbed by these metals [3], as well as by the phase composition and modifying additives of the bearing alloys [2, 5]. However, the data available in various papers differ markedly. These differences are attributed by the authors of [5] to the differences in the methods of catalyst preparation.

A goal-oriented approach to the selection of a catalyst system, which meets a certain number of requirements, is necessary to improve the efficiency of selective hydrogenation of highly unsaturated impurities in hydrocarbon streams. These are: high activity of the catalyst in the hydrogenation process, enabling conversion of impurities to almost $100 \%$, high catalyst selectivity over alkene (at least $80 \%$ ), stability of the catalyst, resistance to poisoning by reaction products, simplicity of production, ease of regeneration and low cost of the catalyst [16-19].

Currently, various supported catalysts are used in industry as selective hydrogenation catalysts to increase the surface of the active component, prevent sintering, and save expensive metal. Platinum group metals: $\mathrm{Pt}, \mathrm{Ph}, \mathrm{Ru}, \mathrm{Pd}$ supported on carriers are used as active components of supported catalysts for hydrogenation of multiple carbon-to-carbon bonds. [20-23]. Despite the high selectivity of hydrogenation, the use of catalysts containing noble metals increases the cost of the process. The most applicable is a nickelbased hydrogenation catalyst having high activity and relatively low cost compared to noble metal catalysts [2].

We have examined in this study the process of hydrogenation of 1-hexene in ethanol and phenylacetylene in a hexane-water suspension over multicomponent nickel skeleton catalysts, the results of which are shown in Tables 1 and 2, and in Figures 1 and 2.

\section{Experimental section}

Preparation of the catalyst. The catalyst was prepared as follows: a sample weight (0.4-0.8 $\mathrm{g}$ ) of crushed, powdered alloy, fraction $0.06-0.20 \mathrm{~mm}$ (the alloy composition is given in Table 1) was processed with $20 \% \mathrm{KOH}$ solution at $96{ }^{\circ} \mathrm{C}$, in a boiling water bath for 2 hours. Water washing from alkali was carried out with distilled water by decantation 4-5 times, up to negative reaction to $\mathrm{OH}$ - ions in washing water. Then, the catalyst was washed with solvent in which hydrogenation was carried out (ethanol).

Methods of conducting experiments. Hydration was performed in a thermostatic "catalytic duck" $[1,2]$ at atmospheric pressure and temperature of $20{ }^{\circ} \mathrm{C}$. The rate of reaction (amount of absorbed hydrogen per unit time, $\mathrm{cm}^{3} / \mathrm{min}$ ) and catalyst potential $(\mathrm{mV})$ relative to the calomel reference electrode were recorded simultaneously by method $[1,2]$. Before the reaction, the catalyst was saturated with hydrogen in the solvent (volume $25 \mathrm{~cm}^{3}$ ) until the reversible hydrogen potential was determined. Hydration was performed in a kinetic regime (700-800 swings/min).

Chromatographic analysis was performed using a Chromos GH-1000 (Chromos, Russia) with flame ionization detector in isothermal mode using BP21 (FFAP) capillary column with polar phase (PEG modified with nitroterephthalate) $50 \mathrm{~m}$ long and $0.32 \mathrm{~mm}$ inner diameter. The column maintained the temperature of $90{ }^{0} \mathrm{C}$, the temperature in the vaporization chamber was $200{ }^{\circ} \mathrm{C}$, the carrier gas was helium, the volume of injection volume was $0.2 \mu \mathrm{l}$. Samples of liquid reaction mixture were taken 2-3 times during the experiment. 
Table 1. Hydrogenation of 1-hexene over multicomponent skeleton nickel catalysts.

\begin{tabular}{|l|l|l|l|l|l|}
\hline $\begin{array}{l}\text { Alloy } \\
\text { composition }\end{array}$ & $\begin{array}{l}\text { Ni-Al-Me } \\
\text { content, } \mathrm{wt} \%\end{array}$ & ${ }^{*} \mathrm{~W}_{\mathrm{C} \equiv \mathrm{C}}$ & $\Delta \mathrm{E}_{\text {in. }}$ & $\mathrm{K}_{\mathrm{s} .}$ & $\mathrm{S}_{\mathrm{t}}$ \\
\hline $\mathrm{Ni}-\mathrm{Al}$ & $50-50$ & 120 & 210 & 0.68 & 0.76 \\
\hline $\mathrm{Ni}-\mathrm{Al}-\mathrm{Cu}$ & $30-60-10$ & 295 & 130 & 0.44 & 0.75 \\
\hline $\mathrm{Ni}-\mathrm{Al}-\mathrm{Zn}$ & $28-36-36$ & 275 & 260 & 0.53 & 0.75 \\
\hline $\mathrm{Ni}-\mathrm{Al}-\mathrm{Zr}$ & $45-50-5$ & 117 & 210 & 0.64 & 0.79 \\
\hline $\mathrm{Ni}-\mathrm{Al}-\mathrm{Pb}$ & $40-50-10$ & 196 & 160 & 0.61 & 0.77 \\
\hline $\mathrm{Ni}-\mathrm{Al}-\mathrm{Ta}$ & $45-50-5$ & 210 & 190 & 0.62 & 0.77 \\
\hline $\mathrm{Ni}-\mathrm{Al}-\mathrm{Cr}$ & $47-50-3$ & 110 & 180 & 0.56 & 0.78 \\
\hline $\mathrm{Ni}-\mathrm{Al}-\mathrm{Mn}$ & $40-50-10$ & 58 & 160 & 0.55 & 0.79 \\
\hline $\mathrm{Ni}-\mathrm{Al}-\mathrm{Fe}$ & $45-50-5$ & 82 & 190 & 0.79 & 0.80 \\
\hline $\mathrm{Ni}-\mathrm{Al}-\mathrm{Ti}-\mathrm{Cr}$ & $44-50-3-3$ & 95 & 230 & 0.52 & 0.76 \\
\hline Ni-Al-Mo-Cu & $42-50-3-5$ & 120 & 80 & 0.62 & 0.75 \\
\hline
\end{tabular}

$* W_{\mathrm{C}=\mathrm{C}}-$ specific activity of the catalyst in hydrogenation of 1-hexene $\mathrm{cm}^{3} \mathrm{H}_{2} / \mathrm{min}$-gNi; $\Delta E_{\text {init. }}-$ initial shift of the catalyst potential, $\mathrm{mV} ; S_{\mathrm{t}}$ - stereospecificity (cis-hexene-2 / trans-hexene-2).

\section{Results}

The catalytic activity and isomerizing ability of the skeleton nickel catalyst in the hydrogenation of 1-hexene is strongly affected by modifying the skeleton nickel with various metals (Table 1), which may be associated with a change in the energy state of the adsorbed hydrogen on the catalyst surface.

The data in the table indicate that the results of the chromatographic analysis suggest a high activity of the modified nickel skeleton catalysts in the $-\mathrm{C}=\mathrm{C}$ - bond migration reaction in the process of hydrogenation of 1-hexene. Modification of the skeleton nickel catalyst with $\mathrm{Fe}$ increases the migration coefficient (Kmigr) from 0.68 to 0.79 , while $\mathrm{Cu}, \mathrm{Zn}, \mathrm{Zr}, \mathrm{Cr}$, $\mathrm{Mn}, \mathrm{Pb}, \mathrm{Ta}, \mathrm{Ti}-\mathrm{Cr}$ additives decrease the catalyst ability to shift the $-\mathrm{C}=\mathrm{C}-$ bond $(\mathrm{Kmigr}=0.44-0.64)$.
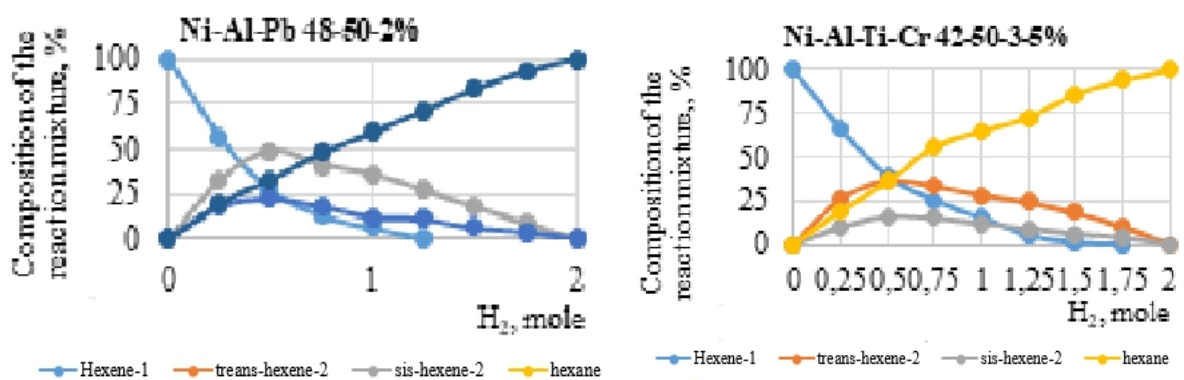

Fig. 1. Changing composition of the reaction mixture during hydrogenation of 1-hexene over skeleton nickel from Ni-Al-Pb (a) and Ni-Al-Ti-Cr (b) alloys (Conditions: $m_{\mathrm{kat}}=0.4 \mathrm{~g}, \mathrm{~T}=200 \mathrm{C}, \mathrm{P}_{\mathrm{H} 2}=0.1$ $\mathrm{MPa}$, Vsolv. $=25 \mathrm{ml}, \mathrm{m}_{\text {hexene }}=2.23 \mathrm{~m} / \mathrm{mol}$ ).

The catalyst activity increases when introducing the metals $\mathrm{Cu}, \mathrm{Zn}, \mathrm{Pb}$, Ta into the bearing alloy $\left(\mathrm{W}=196-295 \mathrm{~cm}^{3} / \mathrm{min}-\mathrm{g} \mathrm{Ni}\right)$, and $\mathrm{Mn}, \mathrm{Fe}$, Ti-Cr additives decrease it $(\mathrm{W}=58$ - 
$95 \mathrm{~cm}^{3} / \mathrm{min}-\mathrm{g} \mathrm{Ni}$ ), while the influence of $\mathrm{Cr}$ and $\mathrm{Zr}$ components is insignificant $(\mathrm{W}=110$ $117 \mathrm{~cm}^{3} / \mathrm{min}-\mathrm{g} \mathrm{Ni}$ ). The strongest adsorption of 1-hexene is found on catalysts containing $\mathrm{Zn}, \mathrm{Zr}(\Delta \mathrm{E}=210-260 \mathrm{mV})$. Alloy alloying with $\mathrm{Cu}, \mathrm{Pb}, \mathrm{Cr}, \mathrm{Ta}, \mathrm{Mn}, \mathrm{Fe}$ and $\mathrm{Cr}$ leads to its decrease $(\Delta \mathrm{E}=130-190 \mathrm{mV})$.

It is thus shown that the activity of multicomponent skeleton nickel catalysts is largely determined by the nature of the additives introduced into the bearing alloy. Introduction of $\mathrm{Cu}, \mathrm{Pb}$ and $\mathrm{Ta}$ leads to growth of activity (W=196-295 $\mathrm{cm}^{3} / \mathrm{min}-$ ). $\mathrm{Zr}, \mathrm{Mn}, \mathrm{Fe}, \mathrm{Cr}$ and Mo$\mathrm{Cr}$ additives do not significantly affect the catalyst activity.

In industrial processes, fine purification of diene compounds from acetylene compounds is performed by the method of selective catalytic hydrogenation in a hydrocarbon solvent [6-11]. The reaction layer of the catalyst may be penetrated by water with the incoming product after the carbonyl cleaning stage. With the purpose of studying the effect of water in hydrocarbon medium on both kinetics and direction of the process of hydrogenation of phenylacetylene $\left(\mathrm{An}_{2}=100 \mathrm{~cm}^{3}\right)$ was conducted on a skeleton catalyst of $\mathrm{Ni}-\mathrm{Al}-\mathrm{Mo}-\mathrm{Cu}$ alloy (42-50-3-5\%) in a solvent of immiscible hexane-water fluids forming an emulsion under intensive stirring. The content of hexane in the emulsion varied from 0 to 100 vol.\% on retention of the total volume of solvent (Table 2, Fig.2,3).

By adding a little water to hexane (2-8\%) hydrogenation rate of phenylacetylene decreases by 3 times. With increasing of water content in emulsion from 2 to $98 \%$ the saturation rate of phenylacetylene increases by 2.5 times. Emulsions reach their maximum saturation rate at $2-4 \%$ hexane content $\left(18-21 \mathrm{~cm}^{3} / \mathrm{min}\right)$. In water, the hydrogenation rate of phenylacetylene (except for individual styrene) is 2.5-3.5 times lower than in emulsions with the content of $2-4 \%$ hexane. When the concentration of water in the emulsions decreases from 98 to $2 \%$, the Ks of phenylacetylene decreases from $0.83-0.85$ to $0.50-0.55$.

Table 2. Hydrogenation of phenylacetylene in hexane-water emulsion over skeleton catalyst of NiAl-Mo-Cu alloy (42-50-3-5\%). Alloys weighted portion is $0.8 \mathrm{~g}$.

\begin{tabular}{|c|c|c|c|c|c|c|}
\hline \multirow{2}{*}{$\begin{array}{l}\text { Emulsion composition } \\
\text { (vol.\%) } \\
\text { Hexane-water }\end{array}$} & \multicolumn{2}{|c|}{$\begin{array}{c}\text { Hydrogenation rate } \\
\mathrm{W}, \mathrm{cm}^{3} / \mathrm{min}\end{array}$} & \multirow[t]{2}{*}{${ }^{*} \mathrm{~K}_{\mathrm{s}}$} & \multirow[t]{2}{*}{6} & \multirow[t]{2}{*}{$\frac{B_{p h}}{B_{\text {st. }}}$} & \multirow{2}{*}{$\begin{array}{l}\mathrm{W}_{\mathrm{C}}=\mathrm{C} \\
\text { ind. } \\
\text { styrene } \\
\mathrm{cm}^{3} / \\
\text { min }\end{array}$} \\
\hline & $\mathrm{C} \equiv \mathrm{C}$ & $\mathrm{C}=\mathrm{C}$ & & & & \\
\hline $0-100$ & 8 & 15 & 0.85 & 0.17 & 9.2 & 15 \\
\hline $2-98$ & 18 & 35 & 0.83 & 0.17 & 4.1 & 15 \\
\hline $4-96$ & 21 & 37 & 0.81 & 0.30 & 1.9 & 15 \\
\hline $12-88$ & 20 & 32 & 0.70 & 0.50 & 1.1 & 14 \\
\hline $20-80$ & 20 & 29 & 0.62 & 0.84 & 0.6 & 13 \\
\hline $40-60$ & 20 & 25 & 0.57 & 1.0 & 0.5 & 9 \\
\hline $50-50$ & 17 & 20 & 0.55 & 1.0 & 0.5 & 7 \\
\hline $60-40$ & 15 & 15 & 0.52 & 1.0 & 0.5 & 6 \\
\hline $80-20$ & 10 & 10 & 0.52 & 1.0 & 0.5 & 4 \\
\hline $92-8$ & 9 & 9 & 0.50 & 1.0 & 0.5 & 3 \\
\hline $98-2$ & 8 & 8 & 0.50 & 1.0 & 0.5 & 2 \\
\hline $100-0$ & 27 & 43 & 0.84 & 0.18 & 5.0 & 25 \\
\hline
\end{tabular}

\footnotetext{
$\frac{B_{p h}}{B_{s t}}$

${ }^{*} \mathrm{~K}_{\mathrm{S}}$ - selectivity coefficient; $\alpha$ - selectivity index; $\overline{B_{\text {st. }}}=$ ratio of adsorption coefficients from the ratio of the components of the mixture of phenylacetylene and styrene.
} 


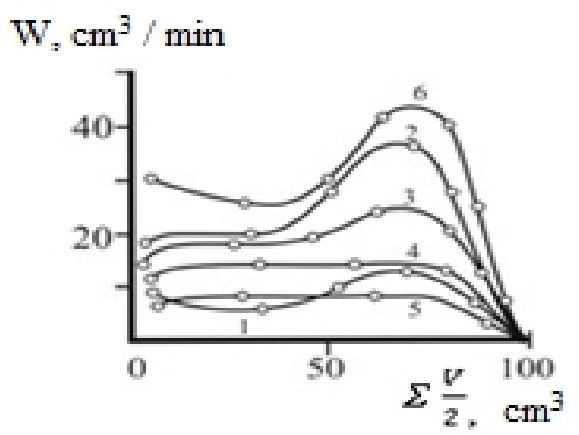

Fig. 2. Curves of hydrogenation of pheniacetylene $\left(\mathrm{AH}_{2}=100 \mathrm{~cm}^{3}\right)$ over a skeleton nickel catalyst of Ni-Al-Mo-Cu alloy (42-50-3-5\%) in solvents 1 - water, 2 - 4\%-hexane-96\% water, 3 - 40\%-hexane$60 \%$ water, 4 - 60\%-hexane-40\% water, 5 - 92\%-hexane- $8 \%$ water, 6 - hexane.

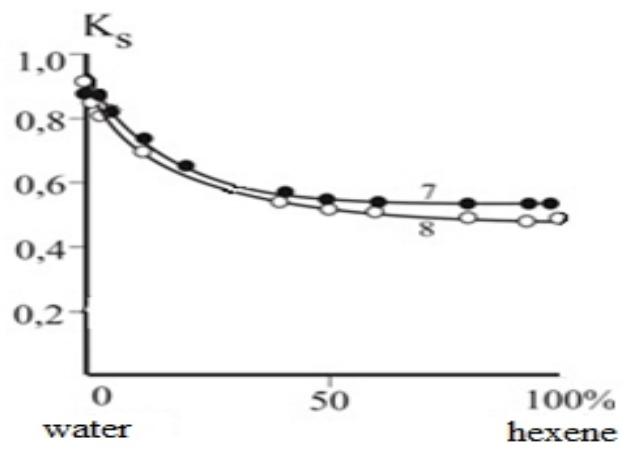

Fig. 3. Dependences of selectivity coefficient of hydrogenation of phenylacetylene in mixture $\mathrm{K}_{S}-1$, selectivity coefficient of hydrogenation of individual phenylacetylene $\mathrm{K}_{\mathrm{S}}-2$ over a catalyst of Ni-Al$\mathrm{Mo}-\mathrm{Cu}$ alloy (42-50-3-5\%) on the composition of hexane-water emulsion.

When studying the hydrogenation reaction of phenylacetylene in hexane-water emulsions over Ni-Mo-Cu catalyst it was found that the presence of water in the hydrocarbon solvent has a strong influence on the kinetics and direction of saturation processes. Regularities of dependence of rate and selectivity of hydrogenation of phenylacetylene on emulsion composition are of extreme nature. (Table 2, Fig. 2, 3)

A sharp fall-off in the rate of hydrogenation of phenylacetylene in emulsions with a low water content $(2-20 \mathrm{vol} . \%)$ is caused by a decrease in the contact surface "catalyst substance solution in hexane" due to "sticking" of particles in the catalyst surrounded by a water mass. Maximum saturation rate of phenylacetylene in emulsions at low concentrations (2-4\%) of hexane is associated with an increase in the number of dispersed water droplets with catalyst particles with increasing water content and reaching the maximum high contact surface of the catalyst and the reacting agent.

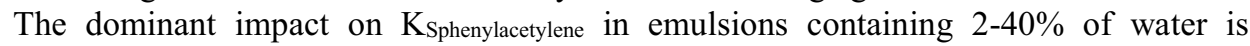
caused by changes in the distribution coefficients of phenylacetylene between hexane and water, and the factor of adsorption displacement recedes into the background. When the contact surface "catalyst - substance solution in hexane" decreases, the increased solubility 
of styrene in compared to phenylacetylene causes a decrease in the ratio of adsorption coefficients $\mathrm{B}_{\mathrm{ph}} / \mathrm{B}_{\text {st }}$ to $0.5\left(\mathrm{~K}_{\mathrm{S}}=0.50-0.55\right)$.

The basic mechanism of the effect of the emulsion composition on the rate and selectivity of hydrogenation of phenylacetylene lies in the change in the distribution coefficient of substances between the solution and the surface of the skeleton nickel catalyst (salting effect) [12-15]. According to the results obtained, we can conclude that the presence of water, competing in adsorption with unsaturated hydrocarbons, adversely affects the process of purification from acetylene hydrocarbons, as well as the stereoregular polymerization of the monomer.

In summary, the results of studies of the kinetics and direction of phenylacetylene hydrogenation processes point to the strong influence of the adsorption factor, including the ratio of free energies, concentrations, and spatial orientation of the molecules of the mixture components, as well as the interaction of the reacting substances and hydrogen with the catalyst surface.

\section{References}

1. D.Sokolsky. Gidr.v rast. 364 p, (1979)

2. D.Sokolsky, V.Druz. Vveden.v teor. 215 p, (1981)

3. B.Kazanski. Katal.prev.uglevod. 632 p, (1968)

4. A.Fasman, G Pushakareva, V.F.Timofeeva. Izomer.geksena-1 pri gidr. Zh.fiz.khimya, 52, 696 p, (358)

5. G Bond, G Webb. Ru and Os an hydr. J.Catalysis, 74 p, (1962)

6. V Stytsenko, D Melnikov, Selekt.gidr.dienovyh i aseti. Zh.fiz.khimya, 90, 691702 p, (2016)

7. N.Plate, E.Slivinski. Osn.khimii i tehn.,696 p.(2002)

8. Ertl G., Knozinger H.,Schuth F., Weitkamp J. Handbook od heter.. 2165 p. (1997)

9. 9.J.Boitiaux, J Cosyns, E.Robert, Applied Catalysis, 32, 145 p, (1987)

10. E.Hrenov, E.Perminova, I Falkov. Kat. i proc. selek i gir. №2, 67 p, (1993)

11. N.Ostrovski. Kin. deakt. kat. p 334 (2011) J.Boitiaux, J Cosyns, M Derrien, 51 p, (1985)

12. S.Matar, I Hatch. Chemistry of petr.prosess. p.238-261, (2001)

13. F.Zhang, X., X Huang. Preprints-american Chem.society, 53, 129 p. (2008)

14. G.Zakumbaeva. Vzaim.org.soed., 304 p, (1978)

15. A.Barenblum, H.Al-Vadhov, E.Kasman. Nanes.palled.nanomater. 55, 125-133 p. (2015)

16. S.Jacson, Sarkany, L.Shaw, Applied Cat. 134, 185 p. (1996)

17. A.Molnar, Sarkany, M Varga, Journ.of mol., 173, 185 p, (2011)

18. S.Nikolaev, L.Zaneveskin, V.Smirnov, V.Averyanov, K.Zanaveskin. Uspehi khimii, 78, 248 p, (2009)

19. E.Harkova, L.Rosanseva, V.Frolov. Gidr.nepred.uglevod. 50, 226-230 p, (2010)

20. E.Harkova, L.Rosanseva, V.Frolov. Kin. i kat. 34, 5 p, (1993)

21. E.Harkova, L.Rosanseva, V.Frolov. Neftekhimya, 41, 2287 p. (2011)

22. E.Harkova, L.Rosanseva, V.Frolov. Kin. i kat. 45, 214 p, (1993) 